Case Report

\title{
Paratesticular Hamartoma in an Infant
}

\section{Amol Dilip Amonkar', Raghu Shankar ${ }^{2}$, Padma Shetty ${ }^{3}$, Sandeep Rai ${ }^{4} \&$ M ohammad Amir ${ }^{5}$}

${ }^{1}$ Postgraduate, ${ }^{5}$ Undergraduate, Department of Surgery, ${ }^{2}$ Associate Professor, ${ }^{4}$ Professor and Head, Department of Pediatric Surgery, Justice K.S. Hegde Charitable Super-specialty Hospital, NITTE University, Mangalore, ${ }^{3}$ Professor, Department of Pathology, Justice K.S. Hegde M edical College, M angalore, Karnataka

*Corresponding Author : Amol Amonkar, Post graduate, Department of Surgery, Justice K.S. Hegde Charitable Super-speciality Hospital, NITTEUniversity, M angalore. Mobile : +919886535829 E-mail : amonkaramol@gmail.com

Received

: 22-09-2015

Review Completed : 01-08-2016

Accepted

: 06-08-2016

\section{Keywords :}

paratesticularhamartoma, benign paratesticular lesion, inguinal exploration

\begin{tabular}{|c|}
\hline Access this article online \\
\hline Quick Response Code \\
\hline
\end{tabular}

\begin{abstract}
:
The benign paratesticular solid lesions havemore often been post-operative histological surprises. We report a rare case of hamartoma of paratesticular region. On inguinal exploration, lesion looked benign and it could be excised completely without opening the tunica. The mass haddisorganised mature tissue consisting of lipocytes, thick walled blood vessels, lymphoid follicles, nerve bundles and smooth muscle tissue, without neoplastic characteristics'. Any suspicious paratesticular lesion warrants an inguinal approach, as we did in our case, to prevent upstaging of the disease incase found to be malignant. However, since benign masses are more common a testicular sparing surgery is possible in a majority of cases.
\end{abstract}

\section{Introduction}

Solid masses in the testicular and paratesticular region are rare in the pediatric age group more so in infancy. Fibrous hamartoma of infancy (FHI), juvenile xanthogranuloma, capillary hemangioma, desmoid tumor, lipoma of the cord are some of the rare pathologic findings among the benign masses in the paratesticular location. We report a case of paratesticularhamartoma in a 10 month old child.

\section{Case report}

A 10 month male child presented with a swelling in the right hemi-scrotum. The swelling was noticed by the parents at 7 months of age. The swelling was not painful and there had been no change in the size. On examination, a $2 \times 1 \mathrm{~cm}$ swelling could be palpated separate from the testis in the right hemiscrotum. It was firm, non-tender and appeared attached to the spermatic cord. Ultrasound revealed a $1 \times 1.5 \mathrm{~cm}$ hypoechoic lesion over postero-medial aspect of the right testis suggestive of hydrocele of the cord or a paratesticular neoplasm. The cord and testis were explored through the inguinal incision. A $1.5 \times 1 \mathrm{~cm}$ solid lesion in close association with the testis was found. There was no evidence of invasion of cord or the testis. A complete excision of the lesion was done without any damage to the testis or the cord. Histopathology showed disorganised mature tissue consisting of lipocytes, thick walled blood vessels, lymphoid follicles, nerve bundles and smooth muscle tissue, foci of fat showed fat necrosis, the necrotic fat being surrounded by neutrophils, foamy macrophages and giant cells. Since the lesion was composed of well differentiated mature structures, and there was absence of neoplastic chararacteristics, a diagnosis of hamartoma was made.

\section{Discussion}

The paratesticular region includes contents of the spermatic cord, rete testis ,testicular tunics, epididymis and vestigeal remnants of Mullerian and Wollffian origin. 

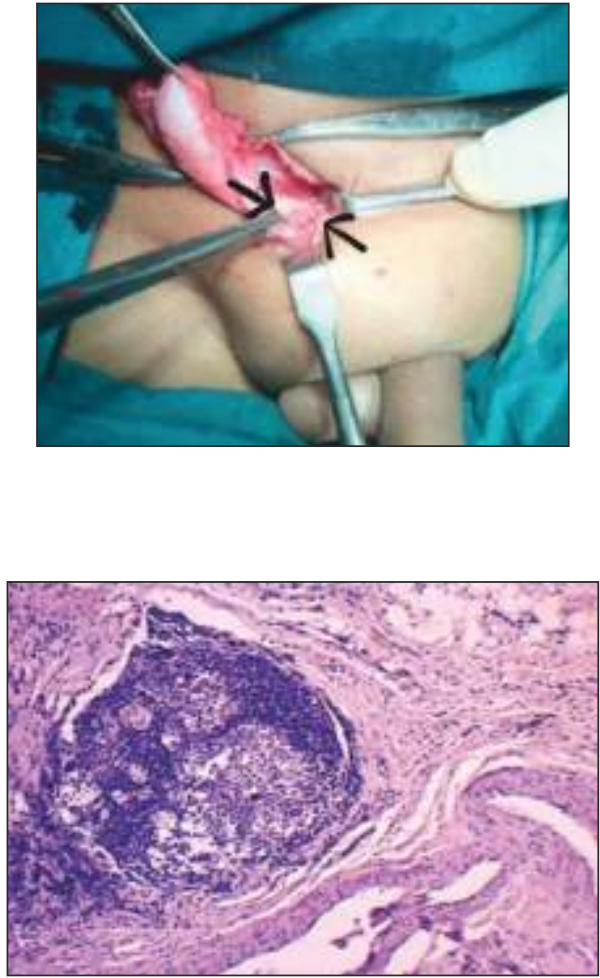

Figure 3: microscopy showingdisorganised mature tissue consisting of lipocytes, thick walled blood vessels, lymphoid follicles, nerve bundles and smooth muscle tissue, foci of fat showed fat necrosis, the necrotic fat being surrounded by neutrophils, foamy macrophages and giant cells.

Histogenetically this area is composed of epithelial, mesothelial and mesenchymal elements. ${ }^{1}$ Paratesticular tumors are rare in the pediatric age group and extremely rare in the infants. In the series which have evaluated the testicular and paratesticular tumors in pediatric age group, benign tumors formed the majority of them. ${ }^{2 \cdot 5}$ The most common pathologic finding was of a mature teratoma. ${ }^{2.5}$ However, when exclusively paratesticular tumors are taken into consideration, the most common histopathologic variant is rhabdomyosarcoma. ${ }^{6}$ Fibrous hamartoma of infancy (FHI), lipoma of the cord, capillary hemangioma, desmoid tumor and juvenile xanthogranuloma are some of the rarer paratesticular lesions reported in the previous literature. ${ }^{4,5,7}$ Other benign diagnoses, such as omental inguinal hernia,inflammatorypseudotumor, and meconium peritonitis have been described in this location; however, in these cases, the mass is usually inside the patent processusvaginalis. ${ }^{8}$ Testicular and paratesticular tumors need to be differentiated from more common

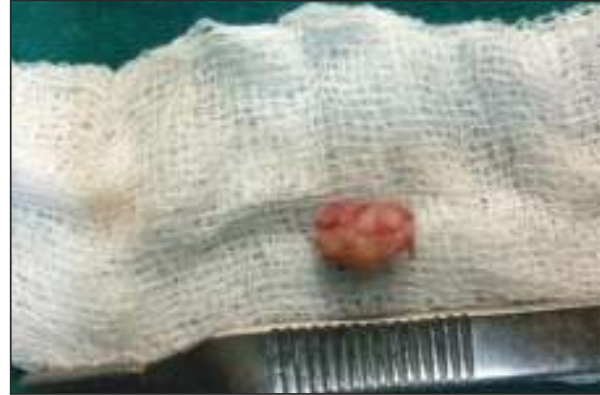

Figure 2 : Excised specimen of paratesticularhamartoma

conditions like inguinoscrotal hernia, hydrocele which can be accomplished clinically in majority of the cases. In some cases it may require a scrotal ultrasound to differentiate between these entities The term hamartoma is used to specify tumor like malformations in which various tissues are present in improper proportions or distributed with prominent excess of one particular tissue.The line of demarcation between a hamartoma and a benign neoplasm is often unclear,as both lesions can be clonal. ${ }^{9}$ hamartomas may be derived from any of the three germinal layers but are most frequently derived from the mesoderm. Though the entire tissue was processed we did not find any ectodermal components and hence teratoma was ruled out.Since the lesion did not show fibroblastic proliferation, the diagnosis of Fibrous hamartoma of Infancy was ruled out. Any suspicious lesion warrants an inguinal approach, as we did in our case, thus preventing the scrotal violation. The lesion, in the present case, looked benign intra-operatively with no local invasion, and it could be excised completely without injuring the testis or the cord.

\section{Conclusion}

We report a rare case of a paratesticular hamartoma other than the FHI. Paratesticular tumors being rare in the infants should be approached with caution. Inguinal incision is ideal to deal with these lesions as possibility of a malignant neoplasm always exists. As benign lesions form majority of the cases, testis sparing surgery should be the first option based on the intraoperative findings. 


\section{References}

1. Lioe TF, BiggartJD.Tumors of the spermatic cord and paratesticular tissue. A clinicopathological study.BrJ Urol 1993;71:600-606

2. Sugita $Y$, Clarnette TD, Cooke-Yarborough $C$, et al. Testicular and paratesticular tumours in children: 30 years' experience. Aust N Z J Surg 1999:69:505-508.

3. Metcalfe PD, Farivar-Mohseni $H$, Farhat $W$, et al. Pediatric testicular tumors: contemporary incidence and efficacy of testicular preserving surgery. J Urol 2003;170:2412-2415 [discussion 2415-6].

4. Murphy F L,LawH,M ushtaql,Sebire N J. Testicular and paratesticular pathology in infants and children:the histopathological experience of a tertiary paediatric unit over a 17 year period.PediatrSurgInt 2007;23:867-872

5. Wang X, XuS ,Tang D, Li M, Wu D, Huang Y. Prepubertal testicular and paratesticular tumors in China:a single-center experience over a 10year period.J PediatrSurg 2012; 47: 1576-1580

6. Eduardo R, Patricio P, Luzia T, María F, Silvia C, Roberto L. Unusual Benign Paratesticular tumor in an infant mimicking Rhabdomyosarcoma. Urology 2008; 71: 1067-1069.

7. SengarM,M ohta A, ManchandaV,Khurana N. Paratesticular fibrous hamartoma in an infant. Singapore M ed J 2012; 53 : e64

8. Sung T, Riedlinger W, Diamond D, et al.Solid extratesticular masses in children: radiographic and pathologic correlation.Am J Roentgenol 2006;186:483-490.

9. M aitra A. Diseases of Infancy and Childhood In : Kumar V, Abbas AK FaustoN,Aster JC (Editors). Robbins and Cotran Pathologic Basis of Disease. Eighth edition; Elsevier Saunders;2010:473. 